\title{
TENSÕES E CONTRADIÇÕES DO ENSINO DE MATEMÁTICA E DA FORMAÇÃO DE PROFESSORES NA ÚLTIMA ETAPA DA EDUCAÇÃO BÁSICA
}

\author{
TENSIONS AND CONTRADICTIONS OF MATHEMATICS AND TEACHER \\ TRAINING IN THE LAST STAGE OF BASIC EDUCATION
}

\author{
OLIVEIRA, Vanesca Almeida de ${ }^{1}$ \\ MARTINS, Elcimar Simão²
}

\begin{abstract}
RESUMO
O Ensino Médio no Brasil é marcado por tensões e contradições estruturais, asseverando a dualidade escolar, intercalando períodos de formação propedêutica e/ou profissional. A última etapa da Educação Básica acumulou durante muitos anos diversos problemas, tais como: baixo investimento financeiro, funcionamento em espaços físicos improvisados, ausência de livros didáticos e de materiais pedagógicos diversos. 0 ensino de matemática carrega o estigma de ser de difícil aprendizado além de contar com alguns professores sem adequada formação. 0 objetivo deste trabalho é refletir sobre as tensões e contradições do ensino de matemática e da formação de professores do Ensino Médio. A metodologia centrou-se na abordagem qualitativa, utilizando o estudo de caso, com entrevistas a doze docentes de quatro escolas públicas de Ensino Médio. Os resultados revelam que as reformas educacionais afetam o Ensino Médio, mas também a formação e o trabalho dos professores.
\end{abstract}

PalaVRas-Chave: Ensino Médio; Formação Docente; Matemática; Reformas educacionais; Ensino e Aprendizagem.

\begin{abstract}
High school in Brazil is marked by tensions and structural contradictions, asserting school duality, interspersing periods of propaedeutic and / or vocational training. The last stage of Basic Education has accumulated many problems for many years, such as: low financial investment, operation in improvised physical spaces, absence of textbooks and diverse pedagogical materials. Teaching math carries the stigma of being difficult to learn and has some teachers without adequate training. The aim of this paper is to reflect on the tensions and contradictions of mathematics teaching and high school teacher education. The

\footnotetext{
${ }^{1}$ Universidade da Integração Internacional da Lusofonia Afro-Brasileira (UNILAB). Acarape, CE, Brasil. e-mail: vanesca.almeida19@gmail.com

${ }^{2}$ Universidade da Integração Internacional da Lusofonia Afro-Brasileira (UNILAB) / Instituto de Ciências Exatas e da Natureza (ICEN) / Mestrado Acadêmico em Sociobiodiversidade e Tecnologias Sustentáveis (MASTS) / Mestrado Profissional em Ensino e Formação Docente (PPGEF UNILAB-IFCE). Acarape, CE, Brasil. e-mail: elcimar@unilab.edu.br
} 
DOI: $10.12957 /$ e-mosaicos.2020.46573

methodology focused on the qualitative approach, using the case study, with interviews with twelve teachers from four public high schools. The results reveal that educational reforms affect high school, but also the training and work of teachers.

KEYwORDS: High School; Teacher training; Mathematics; Educational reforms; Teaching and learning.

\section{INTRODUÇÃO}

O Ensino Médio no Brasil é marcado ao longo de sua trajetória por tensões e contradições estruturais, asseverando a dualidade escolar, intercalando períodos de formação propedêutica e/ou profissional. A última etapa da Educação Básica também acumulou durante muitos anos diversos problemas, tais como: baixo investimento financeiro, funcionamento em espaços físicos improvisados, ausência de livros didáticos para os estudantes e de materiais pedagógicos diversos.

Como importante política pública educacional, a Lei no 11.494/2007, que regulamenta o Fundo de Manutenção e Desenvolvimento da Educação Básica e de Valorização dos Profissionais da Educação (FUNDEB), assegurou o investimento de recursos financeiros a toda a educação básica, contemplando, portanto, da creche ao Ensino Médio. A Emenda Constitucional no 59/2009 assegurou a obrigatoriedade e a oferta gratuita do ensino de quatro a dezessete anos, o que garante aos estudantes do Ensino Médio o acesso a material didático escolar, transporte escolar, alimentação e assistência à saúde.

De todo modo, é preciso refletir que alguns desafios ainda persistem nos dias atuais, como o elevado percentual de professores contratados temporariamente e com formação inadequada à área/disciplina em que exercem a docência. Tais questões têm asseverado indicadores excludentes e um cenário preocupante de inserção social e cultural dos jovens brasileiros (MARTINS, 2018).

A Lei de Diretrizes e Bases da Educação Nacional (LDB) No 9.394/96, em seu Art. 35, aponta que o Ensino Médio é o período final da Educação Básica, tem uma duração mínima de três anos e as finalidades seguintes:

I - A consolidação e o aprofundamento dos conhecimentos adquiridos no ensino fundamental, possibilitando 0 prosseguimento de estudos;

II - A preparação básica para o trabalho e a cidadania do educando, para continuar aprendendo, de modo a ser capaz de se adaptar com flexibilidade a novas condições de ocupação ou aperfeiçoamento posteriores; 
DOI: $10.12957 /$ e-mosaicos.2020.46573

III - O aprimoramento do educando como pessoa humana, incluindo a formação ética e o desenvolvimento da autonomia intelectual e do pensamento crítico;

IV - A compreensão dos fundamentos científico-tecnológicos dos processos produtivos, relacionando a teoria com a prática, no ensino de cada disciplina (BRASIL, 1996).

O Ensino Médio carrega ainda a importante e desafiadora marca de se desenvolver no período em que os estudantes estão em transição para o mundo do trabalho e/ou o Ensino Superior, bem como na complexa mudança da vida de adolescente para adulto.

Assim como as demais etapas, o Ensino Médio necessita de docentes bem formados para desempenharem a complexa tarefa de educar, visto que o professor é o mediador do processo de ensino e de aprendizagem dos educandos. É preciso refletir que processo formativo docente está entrelaçado a aspectos de sua vida e de seu trabalho.

O trabalho docente está configurado em uma dimensão ampla de diversas tarefas, tais como: planejamento de aulas, organização de estratégias, estabelecimento de metas de ensino e de aprendizagem, inovações nas práticas quando preciso, avaliação de desempenho dos estudantes, auto avaliação do trabalho desempenhado e realização de formação continuada para se manter atualizado (OLIVEIRA, 2018).

Na compreensão de Libâneo (2001, p. 9) "[...] o trabalho docente é pedagógico porque é uma atividade intencional, implicando uma direção (embora nem todo trabalho pedagógico seja trabalho docente) ". Partindo dessa premissa, o trabalho docente é intencionalmente organizado com vistas ao trabalho pedagógico de transposição do conhecimento científico em matéria de ensino.

É importante refletir que a Educação, de maneira mais ampla; o Ensino Médio, incluindo o ensino e a aprendizagem de matemática, objetos de estudo deste trabalho, carregam as marcas do tempo histórico em que estão situados, posto que mudam de acordo com as demandas da sociedade, ampliando-se para diversos contextos, como político, econômico, social e cultural, afinal "histórica e universalmente o componente disciplinar Matemática, seus aportes e recursos didáticos integram a educação, os currículos em diferentes etapas e modalidades de ensino" (SILVA, 2016, p. 14).

$O$ relatório Education at a Glance revela que, como meio de elevar as taxas de conclusão do Ensino Médio, o Brasil vem apostando na Educação Profissional (OECT INDICATORS, 2018). É necessário situar que o Decreto no 2.208/97 legitimou a dualidade entre a formação intelectual e a formação para o trabalhador, explicitando a segregação de duas ofertas de ensino: educação geral, destinada aos estudantes favorecidos economicamente; e outra voltada à classe trabalhadora, com foco na 
profissionalização. Essa realidade trouxe implicações diretas aos estudantes de baixo poder aquisitivo, resultando em uma "década perdida" em relação aos processos formativos (KUENZER, 2010).

Por outro lado, o Decreto no 5.154/2004, revoga o Decreto no 2.208/97, com a tentativa de superação da histórica dualidade educacional, propondo a articulação entre a educação profissional técnica e o Ensino Médio. O novo modelo proposto não assegurou a ruptura dual, pois as mudanças estruturais só acontecerão de fato pela "organização dos movimentos sociais, sindicatos e intelectuais, forças políticas e culturais que efetivamente lutam pelos direitos dos trabalhadores" (FRIGOTTO, 2016, p. 68).

Acreditamos que é fundamental um movimento de várias forças em prol da luta por uma educação de qualidade, compreendendo os diversos públicos que estão situados no âmbito da educação básica, em especial no Ensino Médio, do trabalhador ao estudante profissional.

O objetivo deste trabalho é refletir sobre as tensões e contradições do ensino de matemática e da formação de professores no Ensino Médio. A metodologia centrouse na abordagem qualitativa, por meio de um estudo de caráter descritivo exploratório, utilizando-se como instrumento de coleta de dados entrevistas semiestruturadas, com 12 (doze) professores que lecionam Matemática em quatro escolas de Ensino Médio da rede pública estadual de ensino próximas aos 3 (três) campi da Universidade da Integração Internacional da Lusofonia Afro-Brasileira (UNILAB), nas cidades de Redenção e Acarape, ambas no estado do Ceará.

A entrevista se deu em duas partes: a primeira abordava dados gerais de identificação dos entrevistados para que fosse traçado um perfil dos professores participantes; a segunda buscou desvelar as vivências formativas e as práticas pedagógicas de docentes de Matemática do Ensino Médio.

Ressaltamos que as entrevistas foram gravadas e, posteriormente, transcritas. Para fins de análise, nesse texto, foi utilizado o termo "ProfMat" para representação da profissão professor de Matemática, em seguida um número que representou a ordem do professor naquela escola e uma letra (de A a D) para representar a escola que o professor leciona, preservando assim a identidade das escolas e de seus informantes.

Além da Introdução e das Considerações Finais, o texto está organizado em duas seções. Na primeira delas, fazemos uma abordagem teórica das categorias centrais ao estudo: Ensino Médio, Ensino de Matemática e Formação de Professores. Na segunda parte apresentamos os resultados e fazemos a discussão dos achados.

\section{EnSINO MÉdio: do ENSINO DE MATEMÁTICA À FORMAÇÃO DE PROFESSORES}


DOI: $10.12957 /$ e-mosaicos.2020.46573

A última etapa do processo formativo da Educação Básica é o Ensino Médio, que compreende no mínimo os três últimos anos da vida escolar e é composto por um público jovem, que justamente nessa etapa da vida deve optar por uma carreira profissional. Desse modo, o Ensino Médio se configura como uma ponte de acesso ao mundo profissional, seja por meio do ingresso à universidade (escolha de uma carreira com nível superior), ou por meio do trabalho/emprego de modo imediato (OLIVEIRA, 2018).

O Ensino Médio, em especial nas duas últimas décadas pós-LDB 9394/96, passou por uma série de mudanças, mas o fundamental é que os dispositivos legais garantam acesso, permanência e excelência de ensino e aprendizagem para todos, visando diminuir as desigualdades tão presentes na sociedade. Por outro lado, conforme afirma Martins (2018), é preciso ter clareza de que as políticas desenvolvidas nas últimas décadas têm se constituído em falsos avanços em relação à formação integral, promovendo apenas números dissimulados para distrair o real objetivo ao qual as políticas públicas se propõem, qual seja, o atendimento aos acordos estabelecidos com os órgãos multilaterais.

Frigotto $(2016$, p. 69) aborda a necessidade de uma união plural, que constitua uma unidade substancial, "uma interpelação política e ética no plano estratégico da luta contra as fortalezas do capital e seus processos educativos alienadores". 0 que 0 autor propõe se mostra ainda mais necessário com a reforma do Ensino Médio imposta pelo governo de Michel Temer por meio da Medida Provisória (MP) no 746/2016, que foi convertida na Lei no 13.415/2017, instituindo a política de fomento à implantação de Escolas de Ensino Médio em Tempo Integral, alterando a atual LDB e a Lei $n^{\circ}$ $11.494 / 2007$.

É preciso refletir que

Ao longo desses anos a estratégia, em diferentes conjunturas, para se enfrentar o enigma ou o nó do ensino médio tem sido reformas curriculares e alteração da legislação que não enfrentam o problema estrutural da educação brasileira: a dualidade e a desigualdade. Face à insuficiência dessas estratégias, argumentamos que o problema fundamental do ensino médio não é somente de ordem curricular, organizacional ou de gestão, como tanto se tem insistido entre nós (FRIGOTTO; CIAVATTA; RAMOS, 2014, p. 68).

Nesse sentido, a última (contra) reforma do Ensino Médio se deu por meio da Lei no 13.415/2017, que modificou de forma impositiva e não refletida com a comunidade a estrutura base do Ensino Médio brasileiro, sem antes considerar os encargos necessários para tal mudança. 
DOI: $10.12957 /$ e-mosaicos.2020.46573

Atrelada a essas questões impostas pela citada reforma, discussões sobre a reformulação do currículo do Ensino Médio de todo o país vêm ganhando força com a instauração da Base Nacional Comum Curricular (BNCC), por meio da Lei no $13.415 / 2017$, que instaura os chamados itinerários formativos, nos quais o estudante poderá optar por um deles, quais sejam: "I - linguagens e suas tecnologias; II - matemática e suas tecnologias; III - ciências da natureza e suas tecnologias; IV - ciências humanas e sociais aplicadas; $\mathrm{V}$ - formação técnica e profissional" (BRASIL, 2017).

É preciso sinalizar algumas preocupações: será que de fato os estudantes poderão optar ou simplesmente terão que aceitar o itinerário imposto? Como ficará a lotação de professores de uma determinada área quando a escola optar por outra? Sabemos que Matemática e Língua Portuguesa serão prioridade, mas disciplinas como as das Ciências da Natureza não ficarão ainda mais excluídas?

São diversos os questionamentos e, na compreensão de Ciavatta (2018, p. 209), "Nesta concepção de realidade, não temos respostas prontas, mas temos critérios para refletir sobre as opções, sobre os caminhos que se fecham ou que se abrem aos nossos jovens estudantes, e para a formação e o trabalho docente".

As possíveis respostas não são animadoras, pois percebemos o Estado na eterna busca do fazer mais com menos, implicando na redução de recursos e na lógica da eficiência. Esse cenário já era denunciado por Frigotto e Ciavatta (2003, p. 97): "Do ponto de vista da educação, ocorre uma disputa entre o ajuste dos sistemas educacionais às demandas da nova ordem do capital e as demandas por uma efetiva democratização do acesso ao conhecimento em todos os seus níveis".

Ainda nesse âmbito, no final de 2018, a BNCC foi homologada e no momento presente as redes pública e privada encontram-se com o desafio de rever os seus currículos, o que implica pensar e garantir formação aos docentes. Não adianta propor itinerários formativos à "escolha" dos discentes e a possibilidade de diferentes arranjos curriculares às escolas sem assegurar as condições efetivas para a sua materialização.

Na compreensão de Pimenta (2019), é necessário que os estudantes tenham condições efetivas para ler o mundo e sua complexidade. Para tanto, precisam chegar às raízes do conhecimento, questionando os motivos para as (re)formulações, sabendo que não há conhecimento absoluto e que constantemente vivemos mudanças, o que implica avanços, mas também retrocessos.

É fato que os estudantes não são mais os mesmos, as demandas são outras e com o avanço das tecnologias, tudo se torna obsoleto de forma muito rápida. Por esse e outros motivos que o ensino de Matemática vem se modificando, no que se refere à integração do conteúdo e sua relação com as demais disciplinas, assim como objetos matemáticos e a realidade (PEREIRA; VASCONCELOS, 2014). 
DOI: $10.12957 /$ e-mosaicos.2020.46573

Histórica e universalmente a Matemática, seus subsídios e ferramentas fazem parte da educação, dos currículos em etapas e modalidades diversas. Compreendendo a necessidade de modificação do ensino de Matemática, atualmente, contextualizar o processo de ensino para tornar a aprendizagem mais significativa se torna cada vez mais ponto de pauta em estudos sobre o ensino da referida disciplina (SILVA, 2017).

$O$ ensino de Matemática devido à necessidade de modificar-se vem se tornando cada vez mais contextualizado, mas além de despertar nos estudantes o interesse pela Matemática aplicada ao dia ao dia, é necessário também fazer com que estes consigam visualizar a beleza pura da Matemática (MACHADO, D'AMBROSIO, 2014). Dentre outras possibilidades, para que isso ocorra, precisamos de professores bem formados, capazes de desenvolver práticas educativas diferenciadas, pois a ideologia do professor como detentor do conhecimento não se aplica mais à realidade a qual estamos inseridos; essa e outras tendências do passado, entretanto, ainda são possíveis de observar em sala de aula, contudo novos tempos requerem novos métodos (CORTELLA, 2014).

Pimenta (2019) também corrobora que o professor não pode mais ser visto como o detentor do conhecimento e o aluno como mero receptáculo. Precisamos de estudantes que pensem, construam conhecimento e não apenas reproduzam. Para tanto, é preciso que o docente seja capaz de fazer a leitura de mundo com os seus estudantes, o que demanda sólida formação teórica aliada à prática pedagógica refletida.

A contextualização do conteúdo e o seu uso em situações concretas do cotidiano podem fortalecer 0 processo de aprendizagem, instigando os estudantes a experimentar, a aprender. Todavia, isso nem sempre acontece, principalmente com disciplinas que exigem raciocínio lógico.

Nessa perspectiva, a formação continuada se torna um elemento primordial para que os docentes vislumbrem novas possibilidades e desenvolvam novas metodologias para que os estudantes aprendam adequadamente. Como afirma Alves (2007), a formação docente exige (re) fazer o modo de pensar, esforço, cautela e pesquisa sobre a prática pedagógica dos que estão mais atualizados em metodologias e ideologias. É preciso que o professor construa sua práxis pedagógica tendo em vista que "a prática de pensar a prática é a melhor maneira de pensar certo" (FREIRE, 1987, p. 65), e isso se torna possível por meio da formação continuada.

De acordo com as ideias de Pimenta (2012, p. 25-26):

[...] a formação contínua não se reduz a treinamento ou capacitação e ultrapassa a compreensão que se tinha de educação permanente. A partir da valorização da pesquisa e da prática no processo de formação de professores, propõe-se que esta se configure como um projeto de formação inicial e contínua 
DOI: $10.12957 /$ e-mosaicos.2020.46573

articulado entre as instâncias formadoras (universidade e escolas).

A citada pesquisadora dialoga com as ideias de Behrens (1996, p. 124), quando esta propõe a aliança entre teoria e prática em que "O compromisso visado é o profissional envolvido com a práxis, que acredite na investigação como um caminho ininterrupto a ser conquistado na busca da competência docente, e na predisposição para a transformação da prática à luz da teoria".

Para tanto, é preciso ultrapassar a ideia de formação em que um profissional "recebe" e "repassa" como um mero replicador/multiplicador, pois de acordo com Lima (2001), o professor-formador precisa articular: i) conhecimento científico com saberes trabalhados nas escolas; ii) cultura profissional dos docentes e dos alunos-professores; iii) formação acadêmica e práticas pedagógicas dos cursistas; iv) expectativas dos cursistas e a proposta da formação; v) distintas realidades entre o sistema de ensino e a formação contínua.

Tais dimensões se asseveram, sobretudo quando não são oferecidas ao formador as condições necessárias ao desenvolvimento da formação. Urge, portanto, ultrapassar a ideia de fazer mais com menos, pois cada vez mais a educação se aproxima dos princípios de eficácia empresarial.

De modo contrário à lógica do capital, de acordo com Martins (2018), a formação exige um processo mútuo e coletivo entre formador e participantes, legitimando-se como espaço-tempo para estudo, discussão e reflexão. Assim, é um movimento contínuo de idas e vindas do eu (individual) ao nós (coletivo), com vistas à transformação de uma realidade comum aos sujeitos.

Fiorentini et al. (2016) revelam que no cenário atual há uma ampliação de projetos e pesquisas capazes de contribuir para a formação dos professores de Matemática. É preciso refletir que além de adequada formação inicial e contínua, os docentes precisam de valorização social e financeira, investimentos em infraestrutura escolar, equipamentos e materiais pedagógicos, apoio da família, acompanhamento por parte das secretarias de educação municipal ou estadual (MARTINS, 2014).

Por outro lado, ainda percebemos desafios ligados à própria formação, pois estudo de Vidal e Vieira (2016) revela que $28,7 \%$ dos professores da rede estadual de ensino do Ceará lecionam fora de sua área de formação inicial. Essas e outras dificuldades comprometem a identidade do docente, desviando a atenção do professor de seu foco central: criar meios para que os estudantes aprendam (NACARATO, 2016).

Nacarato e Paiva (2013) apontam que o impacto da tecnologia com a ciência abre caminhos para um novo modo de construção e compreensão da Matemática, pois as Tecnologias da Informação e da Comunicação (TICs) vêm interferindo diretamente no cotidiano dos jovens de modo impactante. As TICs, portanto, são vistas muitas vezes como dificuldade, pois tiram o foco dos estudantes, porém se utilizadas de 
maneira estratégica são capazes de abrir novas possibilidades de aproximá-los da Matemática. É fato que os discentes em grande medida têm mais conhecimento dessas tecnologias do que o próprio professor, o que demanda a necessidade de atualização por parte do docente para que possa utilizá-las como estratégia metodológica em sala de aula.

A formação docente deve se renovar constantemente, pois as mudanças ocorrem cada vez mais rápido e "o trabalho docente é parte integrante do processo formativo mais global pelo qual os membros da sociedade são preparados para a participação na vida social" (LIBÂNEO, 2013, p. 14). Corroborando com isso, D'Ambrosio (2012) afirma que a formação dos professores de Matemática ainda é um desafio.

Assim, a formação de professores, em seus mais diversos aspectos, com dificuldades, realidades e contextos diversos está situada em um propósito amplo, o de possibilitar que o ensino e a aprendizagem ocorram da melhor maneira possível, por meio de reflexões sistemáticas e intencionais, aliando conhecimento teórico à vivência prática do cotidiano escolar.

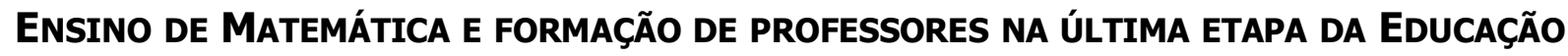 BÁSICA}

O ensino de Matemática, em especial na última etapa da Educação Básica, requer um olhar diferenciado na atualidade para que se torne mais significativo para os estudantes. Tal fato requer do professor atualizar-se sempre que possível, pois a experiência em sala de aula não é suficiente para promover um ensino diferenciado e atual (SOUZA; GOUVEIA, 2012).

Ao refletirem sobre sua área de conhecimento, os pontos de vista dos docentes investigados foram similares, retratando que a Matemática não é uma disciplina adorada pelos estudantes, pois "[...] os alunos não gostam dos números" (ProfMat 1B); "[...] falta de muita afinidade por parte do aluno e da própria dificuldade que ele tem quando chega ao ensino médio" (ProfMat 2B); " [...] os estudantes têm uma aversão muito grande com relação a Matemática" (ProfMat 4). Essa falta de proximidade do aluno com a disciplina se dá algumas vezes pela falta de conhecimentos sobre a disciplina, "lacunas deixadas por vários motivos durante 0 Ensino Fundamental, o que torna o Ensino Médio um momento de revisão, ou de reeducação sobre os fundamentos da Matemática" (ProfMat 4B), pois muitas vezes "os estudantes ingressam sem o domínio sequer das quatro operações fundamentais" (ProfMat 1D) e com o "conhecimento lógico (fundamental em Matemática) não bem trabalhado inicialmente" (ProfMat 3C).

Corroborando com o exposto, Resende e Mesquita (2013) apontam que os professores elencam que as dificuldades dos alunos do Ensino Médio advêm da falta 
DOI: $10.12957 / \mathrm{e}-\mathrm{mosaicos} .2020 .46573$

de base e conhecimento de anos escolares anteriores. Assim, cabe salientarmos a necessidade de investimentos em todas as etapas do processo educacional, não adianta reformular o Ensino Médio, sem levar em consideração a educação básica como um todo.

As dificuldades para aprender Matemática, em especial durante o Ensino Médio, acabam criando alguns mitos e estigmas para a disciplina. De acordo com os entrevistados, a Matemática para os alunos é um "bicho papão" (ProfMat 1B e $1 A$ ), "matéria difícil" (ProfMat 3B, 2A, 3C, 4B), a qual "pouca gente consegue aprender" (ProfMat 3C). Assim, são recorrentes frases como: "eu não consigo aprender, não entra na minha cabeça, eu já cumpri a tabuada, mas eu não consigo" (ProfMat 2B), e isto faz com que muitas vezes os estudantes transfiram a aversão da disciplina ao professor (ProfMat 1D, 2D, 2C), como ainda enfatizado na fala do ProfMat 1A, quando afirma que "geralmente professor de Matemática é aquele carrasco, aquele bruto, é um mito muito grande, é um estigma que a gente carrega também. Ser professor de Matemática é ser chato, é ser bruto, na cabeça deles, professor legal não é para ser professor dessas disciplinas". O ProfMat 2B aponta a afetividade para com os alunos como a maneira de desmistificar a visão que os estudantes têm para com a Matemática e o próprio professor de Matemática, quando fala: "[...] até tem essa dificuldade da gente se aproximar do aluno por ele não gostar da disciplina, mas aí a gente vai entrar com a afetividade, quando a gente entra com a afetividade com 0 aluno a outra parte vai chegando junto" (ProfMat 2B).

Os docentes revelaram que os desafios e os saberes traduzidos com a experiência desvelam a sua identidade docente por meio de uma constante reflexão daquilo que foram e idealizaram ser, o que se tornaram e o que querem ser, enquanto pessoas e educadores, nunca prontos, mas em constante aprendizado, pois "ninguém começa a ser educador numa certa terça-feira às quatro horas da tarde. Ninguém nasce educador ou marcado para ser educador. A gente se faz educador, na prática e na reflexão sobre a prática" (FREIRE, 1991, p. 58).

No cotidiano da prática pedagógica no Ensino Médio o professor percebe que a sua formação inicial não é suficiente. É nesse momento que a formação continuada entra em cena. Na compreensão dos participantes da investigação sobre a formação continuada, obtivemos respostas bem pontuais e positivas traduzidas em expressões como: "não parar de estudar" (ProfMat 1A, 1B, 2A), "atualização" (ProfMat 1D, 2C), "busca do novo" (ProfMat 3C, 4B) "refletir a prática" (ProfMat 2B, 4C), "pesquisar" (ProfMat 3B, 2D) e "troca" (ProfMat 1C). Consideramos o professor como um eterno aprendiz de sua profissão (LIMA, 2001) e a escola um ambiente capaz de proporcionar diversas experiências.

Considerando o Ensino Médio e as atuais mudanças pelas quais vem passando em virtude da Lei $N^{\circ} 13.415 / 2017$, os professores foram convidados a refletir sobre as tensões e contradições desse espaço-tempo. Os professores ficaram divididos entre os que não sabiam opinar se a reforma seria boa ou ruim, os que acreditavam que a 
reforma pudesse trazer contribuições positivas e os que compreendiam que a reforma seria ruim. Apesar da reforma do Ensino Médio ser motivo de impacto na aprendizagem dos alunos e no trabalho do professor, $41,67 \%$ dos professores não sabia comentar acerca do assunto, de modo a termos as seguintes afirmações: "Eu não sei, sinceramente eu não sei, [...] eu não consigo afirmar que realmente é uma reforma boa, ou que não, [...] eu não tenho resposta para essa pergunta" (ProfMat $1 \mathrm{~A}$ ); "Eu não conheço muito a fundo, eu não vou afirmar certas coisas, porque posso estar equivocado" (ProfMat 4C); "Eu já vi sim, mas não muito profundamente" (ProfMat 3C); "Estou muito aérea em relação a reforma, eu não parei ainda para ver como as coisas estão, eu vou de acordo com o que me disserem" (ProfMat 1C); "Eu ainda, não gosto muito de falar, [...] ainda estou pensando, nos pontos positivos e negativos" (ProfMat $2 A)$.

É preocupante verificar que quase metade dos professores que atuam no Ensino Médio das duas cidades estudadas não compreendia a complexidade de um assunto que impacta diretamente em seu campo de trabalho. De modo mais amplo, é necessária a reflexão acerca dos processos políticos em curso no país, que impactam não apenas no Ensino Médio, mas na vida, na formação e no trabalho docente, bem como no exercício e nas condições de autonomia didático-pedagógica das escolas (CIAVATTA, 2018).

No olhar de $25 \%$ dos professores, a reforma do Ensino Médio trará ou esperam que ela traga contribuições positivas, porém não sabiam discorrer muito sobre: "Acredito que de alguma maneira vai ser bom" (ProfMat 1B); "Ela pretende direcionar os alunos pelo interesse deles, [...] tem alunos que se interessam mais com história e com biologia, então, eles vão melhorar muito de qualidade" (ProfMat 3B); "[...] espero que ela ajude ao atual modelo, hoje nós temos um modelo meio que defasado em relação ao público que atendemos e espero que com essa reforma ela possa contribuir tanto no ensino com relação ao professor, quanto para a aprendizagem que é o aluno" (ProfMat $2 \mathrm{C}$ ). O que fica claro na fala desses docentes é que eles querem mudanças no Ensino Médio, mas que trazem conclusões muito pontuais, havendo assim a necessidade de refletirem de maneira mais ampla sobre o assunto. É preciso analisar que os problemas do Ensino Médio estão centrados na desigualdade e na dualidade; vão além do currículo, da organização ou da gestão (FRIGOTTO; CIAVATTA; RAMOS, 2014).

Dentre os docentes que não concordam com as propostas trazidas na reforma do Ensino Médio, um terço dos professores, afirmaram que esta é: "[...] um retrocesso em nossa educação" (ProfMat 2B). De modo que "[...] deveria ter tido um processo" (ProfMat 4B) para acontecer, visto que "a questão das disciplinas é algo não muito bom para a formação do aluno" (ProfMat 1D), "[...] pois a retirada de algumas disciplinas implicará na formação do aluno, em parte humanista" (ProfMat 2D).

Com efeito, de acordo com as ideias de Ciavatta (2018, p. 209): "Não podemos falar em contrarreforma do ensino médio sem refletir sobre os processos políticos em 
DOI: $10.12957 /$ e-mosaicos.2020.46573

curso no país. Eles não afetam apenas o ensino médio, mas também a vida e a formação dos professores", o que implica nas condições para o exercício da docência e a garantia da autonomia das instituições escolares.

Por fim, com base nos achados podemos afirmar que o ensino de Matemática na última etapa da educação básica é repleto de estigmas pelos alunos, o que se traduzem nas dificuldades em acompanhar a disciplina durante o processo de escolarização, deixando assim lacunas que dificultam o gosto pela aprendizagem de Matemática. Dentre outras possibilidades, tal questão só pode ser acentuada com a ajuda do professor, que necessita cada vez mais de formação para compreender a educação, as tensões e contradições impostas pelas reformas educacionais e assim tornar a Matemática mais próxima dos estudantes.

\section{CONSIDERAÇÕES FINAIS}

Este trabalho buscou refletir sobre as tensões e contradições do ensino de matemática e da formação de professores no Ensino Médio. Para tanto, utilizamos uma abordagem qualitativa, por meio de entrevistas com doze professores do Ensino Médio que lecionam Matemática nas cidades de Acarape e Redenção, no Ceará.

Constatamos que, segundo os docentes, a Matemática durante o Ensino Médio é uma disciplina difícil/complexa, devido principalmente ao baixo nível de conhecimentos de Matemática no Ensino Fundamental, o que não propicia aos estudantes visualizar a disciplina como algo associado à sua realidade.

Foi possível compreender que faltam efetivas políticas públicas de melhoria da educação para que o professor de Matemática esteja em constante formação, buscando ponderar, refletir e modificar suas práticas para que os estudantes possam compreender a Matemática como algo presente em suas respectivas realidades.

Por fim, é preciso refletir que as reformas educacionais afetam o Ensino Médio, mas também a formação e o trabalho dos professores, tirando-lhes - algumas vezes sem que percebam - a sua autonomia didático-pedagógica.

\section{REFERÊNCIAS}

ALVES, Eva Maria Siqueira. A ludicidade e o ensino de matemática: uma prática possivel. 4 ed. Campinas: Papirus, 2007.

BEHRENS, Marilda Aparecida. Formação continuada dos professores e a prática pedagógica. Curitiba: Champagnat, 1996. 
DOI: $10.12957 /$ e-mosaicos.2020.46573

BRASIL. Lei no 9.394, de 20 de dezembro de 1996, que estabelece as diretrizes e bases da educação nacional, para dispor sobre a formação dos profissionais da educação e dá outras providências. Brasília, 1996.

BRASIL. Decreto $n^{\circ}$ 2.208/97. Regulamenta o $\S 2^{\circ}$ do art. 36 e os artigos 39 a 42 da Lei no 9.394, de 20 de dezembro de 1996, que estabelece as diretrizes e bases da educação nacional. Brasília: Casa Civil, 1997.

BRASIL. Decreto No 5.154/2004. Regulamenta o § $2^{\circ}$ do art. 36 e os arts. 39 a 41 da Lei no 9.394, de 20 de dezembro de 1996, que estabelece as diretrizes e bases da educação nacional, e dá outras providências. Brasília: Casa Civil, 2004.

BRASIL. Lei 11.494/2007. Fundo de Manutenção e Desenvolvimento da Educação de Valorização dos profissionais da Educação Básica. Fundeb. Brasília: SEB/MEC, 2007.

BRASIL. Projeto de Lei 3891/2008. Dispõe sobre a criação da Universidade Federal da Integração Luso-Afro-Brasileira - UNILAB e dá outras providências. Brasília:

Câmara dos Deputados, 2008. Disponível em:

<http://www.camara.gov.br/proposicoesWeb/fichadetramitacao?idProposicao $=40766$ 0>. Acesso em: 10 mar. 2018.

BRASIL. Emenda Constitucional no 59, de 11 de novembro de 2009. Brasília: Casa Civil, 2009.

BRASIL. Medida Provisória No 746, de 22 de setembro de 2016, que institui a Política de Fomento à Implementação de Escolas de Ensino Médio em Tempo Integral e dá outras providências. Brasília: Casa Civil, 2016.

BRASIL. Lei no 13.145, de 16 de fevereiro de 2017, que institui a Política de Fomento à Implementação de Escolas de Ensino Médio em Tempo Integral. Brasília: Casa Civil, 2017.

CIAVATTA, Maria. A reforma do ensino médio: uma leitura crítica da lei $n$. 13.415/2017 - adaptação ou resistência? Holos, ano 34, v. 04, p. 207-228, 2018.

CORTELLA, Mario Sergio. Educação, Escola e Docência: novos tempos, novas atitudes. São Paulo: Cortez, 2014.

D'AMBROSIO, Ubiratan. Educação Matemática: da teoria à prática. 23 ed. Campinas: Papirus, 2012.

FIORENTINI, Dario. et al. O professor que ensina matemática como campo de estudo: concepção do projeto de pesquisa. FIORENTINI, Dario; PASSOS, Cármen Lúcia Brancaglion; LIMA, Rosana Catarina Rodrigues de. (Orgs). Mapeamento da 
DOI: $10.12957 /$ e-mosaicos.2020.46573

pesquisa acadêmica brasileira sobre o professor que ensina matemática (2001-2012). Campinas: UNICAMP, 2016.

FREIRE, Paulo. Educação e mudança. Rio de Janeiro: Paz e Terra, 1987.

FREIRE, Paulo. A Educação na Cidade. São Paulo: Cortez, 1991.

FRIGOTTO, Gaudêncio. Uma década do Decreto no 5.154/2004 e do proeja: balanço e perspectivas. Holos, Ano 32, Vol. 6, p. 56-70, 2016.

FRIGOTTO, Gaudêncio; CIAVATTA, Maria. Educação básica no brasil na década de 1990: subordinação ativa e consentida à lógica do mercado. Educ. Soc., Campinas, v. 24, n. 82, p. 93-130, abril 2003.

FRIGOTTO, Gaudêncio; CIAVATTA, Maria; RAMOS, Marise. A educação de trabalhadores no brasil contemporâneo: um direito que não se completa. Germinal: Marxismo e Educação em Debate, Salvador, v. 6, n. 2, p. 65-76, dez. 2014.

KUENZER, Acácia Zeneida. O Ensino Médio no Plano Nacional de Educação 20112020: superando a década perdida? Educ. Soc., Campinas, v. 31, n. 112, p. 851-873, jul.-set. 2010.

LIBÂNEO, José Carlos. Didática. 2 ed. São Paulo: Cortez, 2013.

LIBÂNEO, José Carlos. Pedagogia e pedagogos: inquietações e buscas. Educar, Curitiba, n. 17, p. 153-176. 2001.

LIMA, Maria Socorro Lucena Lima. A formação contínua do professor nos caminhos e descaminhos do desenvolvimento profissional. Tese de Doutorado. USP, 2001.

MACHADO, Nílson José; D'AMBROSIO, Ubiratan. Ensino de matemática: pontos e contrapontos. São Paulo: Sammus, 2014.

MARTINS, Elcimar Simão. Educação das Relações Étnico-Raciais e Formação de Professores de Ciências da Natureza e Matemática: um Estudo em Escolas de Ensino Médio do Maciço de Baturité/CE. Relatório (Pós-doutorado) - Faculdade de Educação, Universidade de São Paulo, São Paulo, 2018.

MARTINS, Elcimar Simão. Formação contínua e práticas de leitura: o olhar do professor dos anos finais do ensino fundamental. 2014. Tese (Doutorado em Educação) - Universidade Federal do Ceará, Fortaleza, 2014.

NACARATO, Adair Mendes; PAIVA, Maria Auxiliadora Vilela. A formação do professor que ensina Matemática: perspectivas e pesquisas. Rio de Janeiro: Autêntica, 2013. 
DOI: $10.12957 /$ e-mosaicos.2020.46573

NACARATO, Adair Mendes. et al. Tendências das pesquisas brasileiras que têm o professor que ensina matemática como campo de estudo: uma síntese dos mapeamentos regionais. In: FIORENTINI, Dario; PASSOS, Cármen Lúcia Brancaglion; LIMA, Rosana Catarina Rodrigues de. (Orgs). Mapeamento da pesquisa acadêmica brasileira sobre o professor que ensina matemática (2001-2012). Campinas: UNICAMP, 2016.

OECT Indicators. Education at a Glance 2018: Brazil - Country Note. OECT, 2018.

OLIVEIRA, Vanesca Almeida. Vida, Formação e Trabalho do Professor De

Matemática: Um Estudo em Escolas De Ensino Médio nos Municípios de Redenção e Acarape/Ce. Trabalho de Conclusão de Curso (Graduação em Ciências da Natureza e Matemática, habilitação em Matemática). Acarape: UNILAB, 2018.

PEREIRA, Ana Carolina Costa.; VASCONCELOS, Cleiton Batista. Construindo uma proposta pedagógica por meio de materiais manipulativos: apresentando a fatoração algébrica estudada no LABMATEN/UECE. In: PEREIRA, Ana Carolina Costa (Orgs.). Educação Matemática no Ceará: os caminhos trilhados e as perspectivas. Fortaleza: Premius, 2014.

PIMENTA, Selma Garrido. Atual proposta de formação de professores entende o educador como um executor. Entrevista concedida a Ingrid Matuoka. Centro de Referências em Educação Integral. Novembro, 2019. Disponível em:

https://educacaointegral.org.br/reportagens/formacao-de-professores-selma-garrido/ Acesso em: 08 nov. 2019.

PIMENTA, Selma Garrido. Professor reflexivo: construindo uma crítica. In: PIMENTA, Selma Garrido; GHEDIN, Evandro. (Orgs.). Professor reflexivo no Brasil: gênese e crítica de um conceito. 7. ed. São Paulo: Cortez, 2012.

RESENDE, Giovane; MESQUITA, Maria da Gloria Bastos de Freitas. Principais dificuldades percebidas no processo ensino-aprendizagem de matemática em escolas do município de Divinópolis, MG. Educação Matemática Pesquisa. v.15, n.1, p. 199222, 2013.

SILVA, Assis Anderson Ribeiro da. Estado do Conhecimento da produção acadêmica discente na pós-graduação stricto sensu no Brasil entre 1987-2015 sobre Educação Matemática nos Países Africanos de Língua Oficial Portuguesa (PALOP). Trabalho de Conclusão de Curso (Graduação em Ciências da Natureza e Matemática, habilitação em Matemática). Acarape: UNILAB, 2016.

SILVA, Thiago Almeida; COSTA, Ramon Gomes. Usando recursos interativos da Web para apoiar o processo ensino-aprendizagem em escolas de Ensino Médio brasileiras. Revista de Ciência, Tecnologia e Inovação. v.2 n.3, p. 38-47, 2017. 
DOI: $10.12957 /$ e-mosaicos.2020.46573

SOUZA, Ângelo Ricardo de; GOUVEIA, Andréa Barbosa. Os trabalhadores docentes da educação básica no Brasil em uma leitura panorâmica. In: OLIVEIRA, DALILA ANDRADE; VIEIRA, Lívia Fraga. (Orgs.). Trabalho na educação básica: a condição docente em sete estados brasileiros. Belo Horizonte: Fino Traço, 2012.

VIDAL, Eloisa Maia; VIEIRA, Sofia Lerche (Orgs). Políticas de Ensino Médio no Ceará: escola, juventude e território. Fortaleza: CENPEC, 2016.

Recebido em 10 de novembro de 2019

Aceito em 22 de maio de 2020

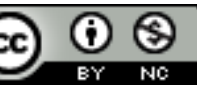

A e-Mosaicos Revista Multidisciplinar de Ensino, Pesquisa, Extensão e Cultura do Instituto de Aplicação Fernando Rodrigues da Silveira (CAp-UERJ) está licenciada com uma Licença Creative Commons - Atribuição-NãoComercial 4.0 Internacional.

Os direitos autorais de todos os trabalhos publicados na revista pertencem ao(s) seu(s) autor(es) e coautor(es), com o direito de primeira publicação cedido à e-Mosaicos.

Os artigos publicados são de acesso público, de uso gratuito, com atribuição de autoria obrigatória, para aplicações de finalidade educacional e não-comercial, de acordo com o modelo de licenciamento Creative Commons adotado pela revista. 